IZA DP No. 10006

Effects of Credit Supply on Unemployment and Inequality

Subhayu Bandyopadhyay

Elias Dinopoulos

Bulent Unel

June 2016 


\title{
Effects of Credit Supply on Unemployment and Inequality
}

\author{
Subhayu Bandyopadhyay \\ Federal Reserve Bank of St. Louis \\ and IZA \\ Elias Dinopoulos \\ University of Florida \\ Bulent Unel \\ Louisiana State University
}

\section{Discussion Paper No. 10006 \\ June 2016}

IZA
P.O. Box 7240
53072 Bonn
Germany

\author{
Phone: +49-228-3894-0 \\ Fax: +49-228-3894-180 \\ E-mail: iza@iza.org
}

\begin{abstract}
Any opinions expressed here are those of the author(s) and not those of IZA. Research published in this series may include views on policy, but the institute itself takes no institutional policy positions. The IZA research network is committed to the IZA Guiding Principles of Research Integrity.

The Institute for the Study of Labor (IZA) in Bonn is a local and virtual international research center and a place of communication between science, politics and business. IZA is an independent nonprofit organization supported by Deutsche Post Foundation. The center is associated with the University of Bonn and offers a stimulating research environment through its international network, workshops and conferences, data service, project support, research visits and doctoral program. IZA engages in (i) original and internationally competitive research in all fields of labor economics, (ii) development of policy concepts, and (iii) dissemination of research results and concepts to the interested public.
\end{abstract}

IZA Discussion Papers often represent preliminary work and are circulated to encourage discussion. Citation of such a paper should account for its provisional character. A revised version may be available directly from the author. 


\section{ABSTRACT}

\section{Effects of Credit Supply on Unemployment and Inequality*}

The Great Recession, which was preceded by the financial crisis, resulted in higher unemployment and inequality. We propose a simple model where firms producing varieties face labor-market frictions and credit constraints. In the model, tighter credit leads to lower output, lower number of vacancies, and higher directed-search unemployment. Where workers are more productive at higher levels of firm output, lower credit supply increases firm capital intensity, raises inequality by increasing the rental of capital relative to the wage, and has an ambiguous effect on welfare. At initial high levels of labor share in total costs tighter credit lowers welfare. This pattern reverses during an expansionary phase caused by higher credit availability.

JEL Classification: D43, E24, G21, J31, J64, L11

Keywords: monopolistic competition, functional inequality, search unemployment, credit constraints

Corresponding author:

Subhayu Bandyopadhyay

Research Division

Federal Reserve Bank of St. Louis

PO Box 442

St. Louis, MO 63166-0442

USA

E-mail: Subhayu.Bandyopadhyay@stls.frb.org

\footnotetext{
* The views expressed are those of the authors and do not necessarily represent official positions of the Federal Reserve Bank of St. Louis or the Federal Reserve System.
} 


\section{Introduction}

Several recent studies have documented the increasing inequality in the United States as well as many other countries. ${ }^{1}$ Economists have proposed several explanations for the rise in income inequality. For instance, Piketty (2014) argues that when the rental of capital exceeds the growth rate of the economy there will be a tendency for income inequality to rise: capital income will be increasing at the rate of capital rental whereas national income will be increasing at the growth rate of the economy. Acemoglu and Robinson (2015) propose a framework with endogenous evolution of institutions interacting with political-economy forces which determines the long-run evolution of inequality; Jones and Kim (2015) focus on the evolution of entrepreneurial (human) capital and its interaction with the process of creative destruction as the primary force shaping top incomes.

These insights apply to an expanding economic universe where incomes experience exponential growth. In other words, the aforementioned studies investigate the forces that govern the evolution of inequality during "good times." What are the forces that affect income and wealth inequality during "bad times" where incomes decline and unemployment rises? One could argue that rising inequality is worse when it occurs during bad times than good times. The financial crisis of 2007 which was followed by the Great Recession is a case in point. According to Perri (2013), income inequality increased during the Great Recession: top income earners experience a 4 percent decline in their incomes, the median household income declined by 9 percent, and the bottom household income decreased by 20 percent (due to a large rise in unemployed members).

The rise in inequality during the Great Recession raises several questions. Did the financial crisis of 2007, which generated a credit crunch, play any role in the rise of unemployment, reduction in aggregate output and divergence of incomes? Under what conditions a reduction in credit availability generates a recession and more inequality?

\footnotetext{
${ }^{1}$ For instance, Piketty and Saez (2003) and Kopczuk (2015) among many others have documented the long-run evolution of top incomes and wealth in the US. Haskel et al. (2012) show that since 2000 average incomes of all groups in the US income distribution have declined except the top one percent. Jones and Kim (2015) present evidence of increasing income inequality in several advanced and developing countries.
} 
What are the welfare effects of tighter credit supply?

To address these questions, we develop a simple general-equilibrium model with credit constraints, directed-search unemployment, and two economic classes, capitalists and workers. The focus on inequality between workers and capitalists is more relevant to wealth inequality between the top 10 percent and the bottom 90 percent, since 10 percent of the population owns around 75 percent of the US wealth (Saez and Zucman 2016).

In our model, the economy is populated by a mass of symmetric firms producing similar products under monopolistic competition. Each product is produced under a nonhomothetic, increasing-returns production technology using capital and labor. Each firm faces an exogenous probability of default and borrows from a competitive banking sector to finance production costs and its capital stock. If the firm does not default, it pays back its loan and keeps its capital stock; whereas if the firm defaults, it does not pay back its loan and its capital stock goes to the bank. Labor-market frictions generate directed-search unemployment in the model. ${ }^{2}$

Consistent with what was observed during the Great Recession, the main finding of the paper is that tighter credit availability captured by higher cost of funds or higher probability of firm default reduces firm and aggregate output, raises the rate of unemployment, and increases income inequality by increasing the rental of capital relative to the expected wage of labor. Intuitively, tighter credit supply raises the rate at which firms borrow from banks, and thus the marginal cost of production. Firms cut output and the number of job vacancies; as a result, aggregate output declines and unemployment rises.

In the presence of non-homothetic production technology, output changes affect the relative demand for labor for any given factor prices. This dependence is governed by the output elasticity of substitution which captures the percentage change in firm capital-labor ratio caused by one percent change in firm output for any given wage and rental. Here, we focus on the case of capital-output substitutability by assuming that a reduction in

\footnotetext{
${ }^{2}$ The production technology is similar to Dinopoulos et al. (2011) who study the effects of intraindustry trade on the skill premium. However, their model assumes away credit constraints and labor-market frictions.
} 
output reduces labor efficiency and therefore makes hired workers more expensive relative to capital for any given factor prices. As a result, firms substitute capital for labor and raise their capital intensity. In other words, a credit induced reduction in firm output reduces the demand for capital by less than the demand for labor raising firm-level capital-labor ratio, the rental of capital relative to the wage, and the share of capital in total production costs. In sum, the presence of non-homothetic production technology coupled with capitaloutput substitutability transmits the recessional effects of lower credit supply to higher inequality between workers and capitalists.

The presence of labor-market frictions and the absence of insurance markets for firm bankruptcy imply that the welfare effects of tighter credit are in general ambiguous. Where the labor share in total costs is high, tighter credit availability reduces aggregate welfare. Recessions are welfare-reducing in this case. Since output changes work through labor efficiency in the present model, the effects of lower output are more profound in the case of high initial labor share in total costs. In this case lower firm output has a greater effect on average firm output and firm productivity than in the case where initial firm labor intensity is low.

Our paper is related to the vast literature on the long-run determinants of income and wealth inequality. A strand of this literature focuses on forces shaping the rental of capital and the wage (Stiglitz 1969, Piketty 2014, Piketty and Saez 2014, Saez and Zucman 2016). Another strand studies economic mechanisms that generate a Pareto distribution of income and/or wealth which captures top inequality within the context of random growth models (Piketty and Saez 2003, Benhabib et al. 2011, Moll 2012, Jones 2015, Jones and Kim 2015). Our paper complements these seminal contributions by investigating how credit availability affects factor prices and macroeconomic variables in the presence of credit imperfections and labor-market frictions.

Although implications of credit-market imperfections have been extensively investigated in many different contexts (such as growth, inequality, investment, trade, etc), the impact of credit constraints on unemployment has not received much attention. Acemoglu 
(2001) develops a model where unemployment rises because job creation stemming from technological progress is constrained by credit-market imperfection. Duygan-Bump et al. (2015) investigate the impact of the Great recession on unemployment in the US, and find that sectors with high external-finance dependence are more likely to experience high unemployment. ${ }^{3}$

The rest of this paper is organized as follows. Section 2 describes the model and discusses its equilibrium properties. The effects of credit availability are investigated in Section 3, and Section 4 concludes.

\section{The Model}

We consider an economy endowed with $K$ units of capital and $L$ workers. Individuals are identical and consume a set of differentiated products each being produced by capital and labor under increasing returns to scale. Each firm produces a distinct variety facing credit constraints and labor-market frictions.

In dynamic settings, firms borrow externally or use retained earnings to finance investments augmenting their capital stock. The absence of insurance markets for firm bankruptcy necessitates the use of assets as collateral. The present model proposes a simple mechanism of credit constraints which mimics the standard dynamic framework. Specifically, we assume that, in the beginning of a single period, firms borrow externally from a competitive banking sector to finance the process of building a factory (consisting of a firm's capital stock). The factory is used as collateral in the borrowing process. After the factory is built, each firm posts job vacancies and completes the worker hiring process. Afterwards, each firm pays its hired workers and produces its product using its factory.

Each firm faces demand-based, product-specific uncertainty: with an exogenous probability $\delta \in(0,1)$ there is no demand for its product, whereas with probability $1-\delta$ the

\footnotetext{
${ }^{3}$ Unel (2016) develops a small-open-economy model to investigate the impact of offshoring on unemployment when firms face credit constraints stemming from limited enforcement.
} 
firm is able to sell its product and repay its loan. In the former case, the firm defaults and its factory (all capital stock) is confiscated by the bank.

Labor-market frictions generate equilibrium unemployment based on directed search. Finally, we assume that income transfers are used to equalize income among individuals. This assumption, which is used routinely in the literature of unemployment, allows us to abstract from unemployment-compensation issues.

\subsection{Consumers}

The country is populated by a unit mass of identical households, each having a fixed supply of $L$ workers. The preferences of the representative household are described by the following utility function over a continuum of goods indexed by $j$ :

$$
U=\left[\int_{j \in \mathcal{J}} y_{j}^{\frac{\varepsilon-1}{\varepsilon}} d j\right]^{\frac{\varepsilon}{\varepsilon-1}}
$$

where $\mathcal{J}$ denotes the set of varieties, $y_{j}$ is the quantity of consumed variety $j$, and $\varepsilon>1$ represents the constant elasticity of substitution between any two goods.

The consumer maximizes her utility subject to the usual budget constraint. The demand for a typical variety is given by

$$
y_{j}=Q\left[\frac{p_{j}}{P}\right]^{-\varepsilon},
$$

where $Q=U$ is aggregate quantity, $p_{j}$ is the price of good $j$, and $P$ is aggregate price given by

$$
P=\left[\int_{j \in \mathcal{J}} p_{j}^{1-\varepsilon} d j\right]^{\frac{1}{1-\varepsilon}} .
$$

Aggregate price $P$ is a dual price index associated with the aggregate quantity $Q$ such that $P Q=E$, where $E=\int p_{j} y_{j} d j$ is consumer total expenditure.

Substituting $Q=E / P$ into (2) and rearranging terms yields the following inverse market demand function

$$
p_{j}=A y_{j}^{-1 / \varepsilon}, \quad A \equiv E^{1 / \varepsilon} P^{(\varepsilon-1) / \varepsilon},
$$

which is more convenient to work with. 


\subsection{Production Technology}

There is a continuum of firms, each producing a different variety. Firms use the same production technology, which exhibits internal (firm-level) economies of scale. We assume that firm-level output $y$ is produced by the following non-homothetic CES production function

$$
y=\left[(\varphi l)^{\frac{\sigma-1}{\sigma}}+k^{\frac{\sigma-1}{\sigma}}\right]^{\frac{\sigma}{\sigma-1}}
$$

where $l$ and $k$ denote labor and capital employed by the typical firm, $\sigma$ is the constant capital-labor elasticity of substitution, and $\varphi$ is a function capturing labor efficiency (productivity) to be specified shortly. ${ }^{4}$ Equation (5) states that output produced depends on capital and labor services with the latter measured in efficiency units. The model can be solved for any $\sigma>0$; however, the case of complementarity between labor and capital leads to comparative statics properties which are not consistent with the main features of the Great Recession. Therefore, we hereafter assume that capital and labor are gross substitutes (i.e., $\sigma>1) .^{5}$

Turning to labor efficiency $\varphi$, we assume that it is a function of market size measured by each firm output as in Dinopoulos et al. (2011). In other words, we assume that larger firms are more productive and exhibit higher labor productivity compared to capital productivity than smaller firms. This assumption leads to a non-homothetic, increasing-returns-to-scale production technology which fits naturally with the monopolistic competition market structure. Specifically, we relate labor efficiency to scale economies

\footnotetext{
${ }^{4}$ Variants of the above CES production function have been widely used in the literature on wage inequality. See, for example, Krusell et al. (2000), Acemoglu (2002), Unel (2010), and Dinopoulos et al. (2011) among many others.

${ }^{5}$ This assumption is consistent with several recent studies, which argue that increased capital intensity and reduced labor's share can only be reconciled by $\sigma>1$ (Elsby et al. 2013, Karabarbounis and Neiman 2014, Piketty and Zucman 2014). Piketty and Zucman (2014), for example, argue that this elasticity must be between 1.3 and 1.6 to be consistent with observed income-inequality patterns in the US and Europe. It should be stated though that there is a large literature that estimate the elasticity of substitution between capital and labor from a production or cost function, and estimates are usually less than one (Lawrence 2015). However, these studies suffer from problems related to omitted-variable bias and reverse causality.
} 
by assuming that

$$
\varphi(y)=y^{\theta}
$$

where $\theta \in(0,1]$, as in Panagariya (1981). Note that (5) becomes the standard constant returns CES production function when $\theta=0$. Where $\theta>0$, the production technology exhibits "labor-saving" increasing returns: as firm output increases labor becomes more efficient leading to lower variable costs as will be established below.

\subsection{Directed-Search Unemployment}

The labor market exhibits frictions leading to search unemployment. Labor-market frictions can be modeled in a variety of ways. In the present paper we focus on directed-search unemployment. Each firm hires workers by posting and maintaining $\nu$ vacancies and offering a firm-specific wage w. Each vacancy involves costs measured in units of capital (i.e., buildings and machines used in the hiring process). ${ }^{6}$ Specifically, we assume that a fixed amount of capital $\phi$ is required for each job vacancy posted. We also assume that capital used in hiring $\phi \nu$ cannot be used in production. All workers search for jobs by directing their search to the firm offering the highest wage $\mathrm{w}$ with each worker applying to only one firm. ${ }^{7}$ A firm posting $\nu$ vacancies faces a measure of $n$ applicants and hires $l<n$ workers. The measure of hired workers is given by the following firm-specific Cobb-Douglas matching function

$$
l=m n^{\gamma} \nu^{1-\gamma},
$$

where $m>0$ is an exogenous parameter representing matching efficiency and $\gamma \in(0,1)$. The above matching function defines the following hiring rate which equals the probability that a worker finds a job

$$
\zeta=l / n=m(\nu / n)^{1-\gamma} .
$$

\footnotetext{
${ }^{6}$ Although in practice worker hiring processes require labor, our assumption captures in an extreme fashion that labor hiring is a capital-intensive activity.

${ }^{7}$ Directed-search unemployment is consistent with evidence provided by Hall and Krueger (2012). They surveyed a sample of US firms and found that about a third of workers had take-it-or-leave-it wage offer. They also found that bargaining is more common among educated workers and about a third of workers had bargained over pay before they were hired.
} 
In sum, each market segment is associated with a single firm, and firm-specific hiring rate $\zeta$ increases with labor-market tightness (job vacancies per applicant $\nu / n$ ).

All workers are searching for jobs and only $\zeta L$ are hired. It follows that the unemployment rate is given by

$$
\mathrm{u}=1-\zeta
$$

where job-finding rate $\zeta$ is given by $(8)$.

\subsection{Cost Structure}

Let $\overline{\mathrm{w}}$ denote the expected wage (income) that each worker obtains at equilibrium. In the absence of unemployment this wage would be identical to the standard wage of labor. Each firm must offer a wage w no less than $\overline{\mathrm{w}}$, otherwise no worker applies to jobs that this firm offers. The CES utility function implies that workers are risk-neutral and thus must be indifferent between a wage offered by a firm and w. In other words, all firms must offer the same expected wage to workers, i.e. $\zeta \mathrm{w}=\overline{\mathrm{w}}$. Without loss of generality we choose the expected wage to be the numeraire by setting $\overline{\mathrm{w}}=1$. In other words, all variables are measured in terms of hired labor.

Substituting (8) into $\zeta \mathrm{w}=1$ yields $\nu / n=(m \mathrm{w})^{-1 /(1-\gamma)}$, which together with (7) yield

$$
\nu=m^{-\frac{1}{1-\gamma}} \mathrm{W}^{-\frac{\gamma}{1-\gamma}} l
$$

It then follows that the total cost of hiring $l$ workers is $r \phi m^{-1 /(1-\gamma)} \mathrm{w}^{-\gamma /(1-\gamma)} l$, where $r$ is the rental price of capital. In addition, firms pay each worker a wage w; as a result, the unit-labor cost (effective wage) is given by

$$
\widehat{\mathrm{w}}=\mathrm{w}+r \phi m^{-1 /(1-\gamma)} \mathrm{w}^{-\gamma /(1-\gamma)}
$$

The total cost of using $l$ workers and $k$ units of capital is $\mathcal{C}=\widehat{w} l+r k$. Each firm chooses the wage it offers $\mathrm{w}$, the measure of workers hired $l$, and the amount of capital $k$ to minimize the total $\operatorname{cost} \mathcal{C}$ subject to producing one unit of output, i.e. $y=1$. This 
minimization problem is recursive: in the first stage, the firm minimizes the cost per hired worker $\widehat{\mathrm{w}}$ with respect to the offered wage $\mathrm{w}$, and then minimizes the total cost $\mathcal{C}$ with respect to $l$ and $k$.

The first stage of the cost-minimization problem generates the following posted wage and the cost per hired worker (effective wage)

$$
\mathrm{w}=\gamma b_{0} r^{1-\gamma} / m, \quad \widehat{\mathrm{w}}=b_{0} r^{1-\gamma} / m
$$

where $b_{0}=\phi^{1-\gamma} /\left[\gamma^{\gamma}(1-\gamma)^{1-\gamma}\right]$. Thus, the wage posted by each firm and the minimum cost per worker hired increase with the price (rental) of capital and the vacancy-capital requirement. In other words, labor-market frictions leading to costly job vacancies imply that the wage and capital rental are positively related, i.e., they are complements (as opposed to substitutes).

In the second stage, each firm minimizes total $\operatorname{cost} \mathcal{C}$ subject to producing one unit of output, i.e. $y=1$. Because the adjusted wage $\widehat{\mathrm{w}}$ is independent of $l$ and $k$, we obtain the following unit-cost function

$$
c(\widehat{\mathrm{w}}, r, y)=\left[\left(\frac{\widehat{\mathrm{w}}}{y^{\theta}}\right)^{1-\sigma}+r^{1-\sigma}\right]^{\frac{1}{1-\sigma}},
$$

where $\sigma>1$. It follows that the total cost of producing $y$ units of output is $\mathcal{C}=c(\widehat{\mathrm{w}}, r, y) y$. Observe that the unit-cost function declines with firm output $y$ indicating the presence of scale economies.

Let $a_{L}$ and $a_{K}$ represent the unit labor and capital requirements of the representative firm. Shephard's lemma delivers the following expressions for these unit-factor requirements:

$$
\begin{aligned}
a_{L}(\widehat{\mathrm{w}}, r, y) & =\frac{\partial c}{\partial \widehat{\mathrm{w}}}=\left(\frac{c}{\widehat{\mathrm{w}}}\right)^{\sigma} y^{\lambda}, \quad \lambda \equiv \theta(\sigma-1), \\
a_{K}(\widehat{\mathrm{w}}, r, y) & =\frac{\partial c}{\partial r}=\left(\frac{c}{r}\right)^{\sigma} .
\end{aligned}
$$

The production technology delivers two elasticities which will play an important role in our subsequent analysis: the traditional wage elasticity of substitution $\sigma$ and the output elasticity of substitution $\lambda$. 
Dividing $a_{K}$ by $a_{L}$ yields the firm-level capital-labor ratio

$$
\frac{a_{K}(z, y)}{a_{L}(z, y)}=z^{-\sigma} y^{-\lambda}
$$

where $z=r / \widehat{\mathrm{w}}$ is the relative rental of capital expressed in units of labor costs. We will refer to $z$ as the adjusted-relative rental of capital. Substituting $\widehat{\mathrm{w}}$ from (12) into $z=r / \widehat{\mathrm{w}}$ yields

$$
z=r / \widehat{\mathrm{w}}=m r^{\gamma} / b_{0}
$$

where $m$ is the matching efficiency and $b_{0}=\phi^{1-\gamma} /\left[\gamma^{\gamma}(1-\gamma)^{1-\gamma}\right]$. According to (16), an increase in $z$ is associated with a rise in $r$ leading to an increase in functional (as opposed to personal) income inequality. In addition, solving (16) for $r$ and using (12) yields

$$
\mathrm{w}=b_{1} z^{(1-\gamma) / \gamma} / m^{1 / \gamma}
$$

where $b_{1}=[\phi /(1-\gamma)]^{(1-\gamma) / \gamma}$. Thus, the wage offered by each firm increases with the adjusted-relative rental of capital, and decreases with efficiency parameter $m$.

Taking logs and differentiating (15) yields the following two elasticities of substitution:

$$
\left|\frac{\partial \ln \left(a_{K} / a_{L}\right)}{\partial \ln z}\right|=\sigma, \quad \quad\left|\frac{\partial \ln \left(a_{K} / a_{L}\right)}{\partial \ln y}\right|=\lambda .
$$

The constant wage elasticity of substitution $\sigma>1$ captures the percentage decline of firm capital-labor ratio caused by one percent increase in the adjusted relative rental of capital, for any given amount of output. As capital becomes more expensive, firms substitute labor for capital reducing their capital-labor ratio.

The constant output elasticity of substitution $\lambda=\theta(\sigma-1)>0$ stems from the nonhomothetic production technology and captures the percentage change in a firm capitallabor ratio caused by one percent change in output, for any given adjusted relative rental of capital. We state that production technology (5) exhibits directed scale effects in the sense that an increase in firm-output reduces the relative demand for capital (i.e., the capital-labor ratio) within each firm. Note that in the present model the output elasticity of substitution $\lambda$ is positive and output has a similar effect as the adjusted-relative rental 
of capital. The unit-cost function (13) indicates that average costs depend on the effective wage of labor $\widehat{\mathrm{w}} / y^{\theta}$. Therefore an increase in output reduces unit labor cost without affecting the rental of capital. As a result, where labor becomes cheaper, the firm substitutes labor for capital reducing its capital-labor ratio (for any given wage and rental rates). This is the case of output-capital substitutability where an increase in output leads to a decline in firm capital-labor ratio.

Another pivotal variable of our analysis is the capital share in total cost:

$$
s(z, y)=\frac{r a_{K} y+r \phi \nu}{c y}
$$

where $\phi \nu$ is the amount of capital allocated to maintaining and posting job vacancies. Substituting $\nu$ from (10) with $l=a_{L} y$ into the above equation and using (12) and (13) yields

$$
s(z, y)=\frac{1+(1-\gamma)\left(z y^{\theta}\right)^{\sigma-1}}{1+\left(z y^{\theta}\right)^{\sigma-1}},
$$

which indicates that $s$ decreases with $z$ and $y$. Equation (20) further implies that $s \in$

$[1-\gamma, 1]$, since $z y^{\theta} \geqslant 0$. In other words, the assumption that capital is needed for vacancy posting imposes a lower bound on the share of capital in total costs $s$.

\subsection{Firm Behavior}

We are now ready to solve the firm value maximization problem. As said, firms face credit constraints and demand-based, product-specific uncertainty: with an exogenous probability $1-\delta$ each firm is able to sell its product and repay its loan; and with probability $\delta$ there is no demand for its product leading to firm default. The representative firm then chooses its output to maximize expected firm value:

$$
\mathbb{E}\left[\Pi_{f}\right]=(1-\delta)[p y+s c y-(1+i) c y]=(1-\delta)[p y-(1+i-s) c y]
$$

where $p$ is the price given by (4), $s$ is the capital share given by (20), $c$ is the unit cost of production given by (13), and $i$ is the interest charged by banks that we shall determine below. According to (21), in the good state of nature (which occurs with probability 
$1-\delta$ ) the firm obtains revenue $p y$ from selling its output plus the value of the factory $s c y=r a_{K} y+r \phi \nu$ (see equation (19)). It also repays its loan $(1+i) c y$, where $i$ denotes the interest charged by banks. In the bad state of nature (which occurs with probability $\delta)$, the firm's value is zero.

When maximizing expected firm value, each firm takes interest rate $i$ as given. The first-order condition yields

$$
p\left(1-\frac{1}{\varepsilon}\right)=(1+i-s) y \frac{\partial c}{\partial y}-c y \frac{\partial s}{\partial y}+(1+i-s) c .
$$

This condition states that each firm chooses its output such that marginal revenue equals credit-adjusted marginal cost. In addition, the assumption of free entry implies that firm expected value must be zero (i.e., $\mathbb{E}\left[\Pi_{f}\right]=0$ ), and thus the price charged must be equal to average credit-adjusted cost (i.e., $p=[1+i-s] c$ ) Substituting this expression for $p$ into the above first-order condition yields

$$
\frac{1}{\varepsilon}=-\frac{y}{c} \frac{\partial c}{\partial y}+\frac{y}{1+i-s} \frac{\partial s}{\partial y} .
$$

Differentiating $c$ from (13) and $s$ from (20) with respect to $y$ leads to

$$
\frac{\partial c}{\partial y}=-\frac{c \theta(1-s)}{\gamma y}, \quad \frac{\partial s}{\partial y}=-\frac{\theta(\sigma-1)(\gamma+s-1)(1-s)}{\gamma y} .
$$

where we use $\left(z y^{\theta}\right)^{\sigma-1} /\left[1+\left(z y^{\theta}\right)^{\sigma-1}\right]=(1-s) / \gamma$ from equation (20). Substituting these expressions into (22) and rearranging the terms yields

$$
\frac{\gamma}{\theta \varepsilon(1-s)}=1-\frac{(\sigma-1)(\gamma+s-1)}{1+i-s}
$$

where $s$ is the capital share in the total cost and $i$ is the interest rate charged by banks.

\subsection{Bank Behavior}

A competitive banking sector supplies credit to firms. ${ }^{8}$ The representative bank borrows funds at an exogenous interest rate $\rho$ and lends to firms at an interest rate $i$. Recall that

\footnotetext{
${ }^{8}$ Feenstra et al. (2011) assume that credit is supplied by a single bank behaving as a monopolist in order to address incomplete-information considerations. In contrast, we assume that credit is provided under complete information.
} 
with probability $1-\delta$ a firm repays its loan and the bank collects $(1+i)$ cy; whereas with probability $\delta$ the firm defaults and the bank collects collateral scy. The bank incurs a total cost of $(1+\rho) c y$ to obtain the necessary funds for each loan. Accordingly, the expected profit of a typical bank is given by

$$
\mathbb{E}\left[\Pi_{b}\right]=(1-\delta)(1+i) c y+\delta s c y-(1+\rho) c y .
$$

Perfect competition among banks drives expected profits down to zero, i.e., $\mathbb{E}\left[\Pi_{b}\right]=0$. Using this property in equation (24), we obtain the following expression for the interest rate charged by banks

$$
i=\frac{\rho}{1-\delta}+\frac{\delta(1-s)}{1-\delta}
$$

where $s$ is the capital share in total cost and given by (20). Equation (25) implies that $i>\rho$, because $\delta<1$ and $s<1$. The interest rate $i$ increases with the cost of funds $\rho$ and declines with the probability of survival $1-\delta$ and the share of costs used as a collateral $s$. In other words, the use of collateral reduces the interest rate on firm loans.

\subsection{Factor Markets}

Let $M$ denote the ex-ante measure of firms in equilibrium. The labor market equilibrium requires that the demand for hired workers equals the measure of workers who find jobs (employed workers). The demand for workers equals $a_{L} y M$ and the supply of employed workers is given by $\zeta L$, where the probability of finding a job is equal to the inverse of the wage offer, i.e. $\zeta=1 /$ w. Thus, the labor-market equilibrium condition is

$$
a_{L} y M=L / \mathrm{w}
$$

where $a_{L}$ is given by (14a) and the posted wage $\mathrm{w}$ is given by (17).

The demand for capital consists of capital devoted to output production and capital used in the hiring process. The former equals $a_{K} y M$ and the latter is equal to $\phi \nu M$. Using $\nu$ from (10) with $l=a_{L} y$, we obtain the following full-employment condition for 
capital

$$
a_{K} y M+\phi a_{L} y \mathrm{w}^{-\gamma /(1-\gamma)} M=K
$$

where the unit-capital requirements $a_{L}$ and $a_{K}$ are given by equations (14a) and (14b), respectively; and $K$ is the economy's capital endowment. This completes the description of our model.

\subsection{Equilibrium Analysis}

This section analyzes the properties of the equilibrium. The first step is determining the equilibrium value of the capital share in total costs, i.e. $s$. Substituting the interest rate $i$ from (25) into (23) leads to the following elasticity condition

$$
\frac{\gamma}{\theta \varepsilon(1-s)}=1-\frac{(1-\delta)(\sigma-1)(\gamma+s-1)}{1+\rho-s}
$$

An economically meaningful solution is obtained under the parameter restriction $\theta \varepsilon>1$, and thus we hereafter assume that $\theta \varepsilon>1 .{ }^{9}$ Parameter $\varepsilon>1$ represents the constant elasticity of substitution between varieties and parameter $\theta>0$ indicates the constant elasticity of labor efficiency with respect to firm output. The LHS of elasticity condition (28) is a convex, increasing function of $s$ starting at $1 / \varepsilon$ (where $s=1-\gamma$ ) and approaching infinity (as $s \rightarrow 1$ ). The RHS of equation (28) is a concave, decreasing function of $s$ starting at 1 (where $s=1-\gamma$ ) and reaching the value of $1-(1-\delta)(\sigma-1) \gamma / \rho$ at $s=1$. It then follows that the two curves defined by the LHS and RHS of (28) intersect only once. The unique intersection determines the general-equilibrium value of $s$.

Lemma 1. There exists a unique $s \in(1-\gamma, 1)$ that satisfies elasticity condition (28).

Once the equilibrium value of capital share in total costs is determined, one can easily solve for other endogenous variables as well. Dividing (27) by (26) and substituting $a_{K} / a_{L}$

\footnotetext{
${ }^{9}$ Note that $\theta=1$ is sufficient for $\theta \varepsilon>1$, since $\varepsilon$ is always greater than one. In other words, we analyze the case where firms face sufficiently large increasing returns to scale.
} 
from (15) into the resulting expression and using (20) yields the equilibrium value for the adjusted relative price of capital:

$$
z \equiv \frac{r}{\widehat{\mathrm{w}}}=m\left(\frac{1-\gamma}{\phi}\right)^{1-\gamma}\left(\frac{s}{1-s}\right)^{\gamma}\left(\frac{\gamma L}{K}\right)^{\gamma} .
$$

This condition implies that higher relative supply of capital (captured by a higher $K / L$ ) puts downward pressure on the relative price of capital, and higher relative demand for capital (captured by a higher $s$ ) exerts upward pressure on the adjusted relative price of capital $z$.

Observe that the offered wage $\mathrm{w}$ is an increasing function of the adjusted relative rental of capital $z$, as given by (17). In addition, determination of $z$ leads to the determination of the rental of capital $r$ and the hiring costs per worker $\widehat{\mathrm{w}}$ based on (16). Output per firm $y$ depends on the share of capital in total costs as well. Solving (20) for $z y^{\theta}$ and substituting $z$ from (29) yields

$$
y=m^{\frac{1}{\theta}}\left[\frac{\phi}{1-\gamma}\right]^{\frac{1-\gamma}{\gamma}}\left[\frac{(1-s) K}{s \gamma L}\right]^{\frac{\gamma}{\theta}}\left[\frac{1-s}{s+\gamma-1}\right]^{\frac{1}{\theta(\sigma-1)}},
$$

which indicates that as the share of capital in total costs rise, output per firm must fall (since $\sigma>1$ ). We can also determine the total output $Y=(1-\delta) M y$, where $M$ is the number of goods produced in equilibrium. Equation (26) implies that $Y=(1-\delta) M y=$ $(1-\delta) L /\left(a_{L} \mathrm{w}\right)$. Using equations (13), (14a), (17), and (20) yields

$$
a_{L} \mathrm{~W}=\frac{s(s+\gamma-1)^{1 /(\sigma-1)} L}{\gamma^{1 /(\sigma-1)} m^{1 / \gamma} K} .
$$

It then follows that the total output $Y$ is given by

$$
Y=\frac{(1-\delta) \gamma^{1 /(\sigma-1)} m^{1 / \gamma} K}{s(s+\gamma-1)^{1 /(\sigma-1)}}
$$

The total output is independent of the total labor supply $L$. It increases with aggregate capital stock $K$ and matching efficiency $m$, and decreases with the share of capital $s$.

The unemployment rate depends on the adjusted relative rental of capital and is calculated as follows. As said, all workers $L$ are searching for jobs but only $\zeta L$ obtain jobs, 
where $\zeta=1 / \mathrm{w}$ is the job-finding rate and $\mathrm{w}$ is the wage offer given by (17). As a result, the rate of unemployment is

$$
\mathrm{u}=1-\zeta=1-\left[\frac{(1-\gamma) m^{\frac{1}{1-\gamma}}}{\phi z}\right]^{\frac{(1-\gamma)}{\gamma}} .
$$

This equation states that unemployment and income inequality measured by the adjusted relative rental of capital are positively related to each other. One may interpret unemployment as the lower bound of extreme inequality: the percentage of individuals with zero income. Furthermore, one can interpret the adjusted relative price of capital $z$ as another source of extreme inequality: an increase in $z$ raises the rental wage ratio $r / w$ benefiting capital owners. ${ }^{10}$ Since capital income is the main source of top income inequality (Piketty and Saez 2014, Jones 2015), our model implies that an increase in the adjusted relative rental of capital raises extreme income inequality.

Finally, we will calculate aggregate welfare. To this end, note that utility function (1) can be written as

$$
U=\left((1-\delta) M y^{\frac{\varepsilon-1}{\varepsilon}}\right)^{\frac{\varepsilon}{\varepsilon-1}}=\left((1-\delta) Y y^{-\frac{1}{\varepsilon}}\right)^{\frac{\varepsilon}{\varepsilon-1}}
$$

and substituting $y$ and $Y$ from equations (30) and (31) into the above equation and ignoring the constant yields the following indirect utility function

$$
\mathbb{V}=\left[\frac{(1-\delta) m^{\frac{\varepsilon-1}{\theta \varepsilon}} K^{1-\frac{\gamma}{\theta \varepsilon}} L^{\frac{\gamma}{\theta \varepsilon}}}{s^{\frac{\theta \varepsilon-\gamma}{\theta \varepsilon}}(s+\gamma-1)^{\frac{\varepsilon-1}{\varepsilon \lambda}}(1-s)^{\frac{1+\gamma(\sigma-1)}{\varepsilon \lambda}}}\right]^{\frac{\varepsilon}{\varepsilon-1}}
$$

where $\lambda=\theta(\sigma-1)$. Note that $\mathbb{V} \rightarrow \infty$ as $s \rightarrow 1-\gamma$ or $s \rightarrow 1$. In addition, taking derivative of $\mathbb{V}$ with respect to $s$ yields

$$
\frac{1}{\mathbb{V}} \frac{d \mathbb{V}}{d s}=-\frac{\theta \varepsilon-\gamma}{\theta(\varepsilon-1) s}-\frac{1}{\lambda(s+\gamma-1)}+\frac{1+\gamma(\sigma-1)}{\lambda(\varepsilon-1)(1-s)}
$$

Note that $d \mathbb{V} / d s<0(d \mathbb{V} / d s>0)$ as the capital share $s$ gets smaller (larger). It then follows that $\mathbb{V}$ is a U-shaped function of $s$. Solving $d \mathbb{V} / d s=0$, one can easily find the

\footnotetext{
${ }^{10}$ Equations (16) and (17) imply that $r / \mathrm{w}=b_{2} z$, where $b_{2}=\gamma(1-\gamma)^{2(1-\gamma) / \gamma}>0$.
} 
capital share $s_{m}$ at which the welfare attains its minimum. Our simulation analysis based on a wide range of parameter values suggests that $s_{m}$ is substantially high (usually above $0.5) \cdot{ }^{11}$

Lemma 2. Aggregate welfare $\mathbb{V}(s)$ is a U-shaped function of the capital share $s$.

\section{Changes in Credit Conditions}

We are now ready to analyze the effects of tighter credit. This is naturally captured by larger costs of external funds $\rho$ and/or higher rate of default $1-\delta$.

Since output elasticity of substitution is positive (i.e., $\lambda=\theta(\sigma-1)>0$ ), a decline in firm output increases the relative demand for capital within each firm. At the initial equilibrium value of $s$, an increase in $\rho$ or a decline in $\delta$ raises the RHS of the elasticity condition (28). To restore the equation, the capital share in total costs, $s$, must increase. This generates a higher equilibrium value of $s$. Equation (23) implies a positive relationship between the interest rate and the share of capital in total costs $s$. As a result, tighter credit availability raises the interest rate banks charge to firms. Equations (29) and (30) imply that tighter credit constraints raise the adjusted relative rental of capital $z$ and reduce firm output $y$. Finally, equation (32) implies that an increase in $z$ raises the rate of unemployment $u$. The following proposition summarizes these findings.

Proposition 1. Tighter credit availability captured by higher cost of funds $\rho$ or higher probability of firm default $\delta$

a. raises the share of capital s;

b. raises the interest rate charged by banks on firm loans $i$;

c. increases income inequality by raising the adjusted-relative rental of capital z;

\footnotetext{
${ }^{11}$ Solving $d \mathbb{V} / d s=0$ yields $s_{m}$ as a highly complicated function of model parameters, and thus simulation analysis is more informative about its value.
} 
d. reduces the output of each firm $y$ and the aggregate output $Y$;

e. and raises the rate of unemployment $u$.

Intuition behind these results are as follows. The zero profit condition (25) requires that a rise in the cost of credit (rise in $\rho$ ) or a reduction in the probability of default (rise in $\delta$ ) must be covered by raising the lending interest rate $i$ at which banks lend to firms. In response to higher interest payments, each firm reduces output produced. The assumption that the output elasticity of substitution is positive (i.e., $\lambda>0$ ) implies that a reduction in firm output reduces firm demand for labor more than firm demand for capital leading to an increase in firm capital intensity. At the aggregate level, this raises the relative demand for capital, and for a given factor abundance, raises the relative price of capital $z$, as well as the absolute price $r$ (see equation (16)).

The rise in the relative demand for capital increases the capital share in costs $s$. This leads to a decline in aggregate output according to equation (31). In other words, a rise in firm costs raises labor cost per unit of output $a_{L} w$ and requires a reduction in aggregate output $Y=(1-\delta) M y$ according to the labor-market equilibrium condition (26). The latter also implies that tougher credit conditions raise the mass of firms $M$. However the reduction in output per firm dominates the increase in the mass of firms leading to a reduction in aggregate output.

The rise in adjusted-relative rental of capital $z$ induces each firm to offer a higher wage $w$ as indicated by equation (17) leading to a reduction in hiring rate $\zeta=1 / w$ and an increase in the rate of unemployment $u=1-\zeta$. Another way ro reveal the mechanism relating lower credit availability to unemployment rate is as follows. Equation (10) indicates that each firm faces a trade off between maintaining vacancies $\nu$ and wage posted $\mathrm{w}$ when considering to hire a worker. A rise in $r$ makes posting vacancies more expensive because of the associated capital cost. This tilts the balance in favor of a higher w (see equation (12)). As firms post higher wages, they reduce the number of vacancies $\nu$, and keep the expected wage $\zeta \mathrm{w}$ constant at unity. As vacancies fall, $\zeta$ must fall as 
indicated by (8), which means that the unemployment rate $u=1-\zeta$ must rise.

Next we analyze how an increase in costs of external funds $(\rho)$ and/or default rate $(\delta)$ affects welfare. In general, the presence of labor-market frictions, monopolistic competition, and collateral requirements generates a second-best market environment. This means that changes in credit conditions affect welfare through changes in consumed varieties captured by the elasticity of substitution in consumption $\varepsilon$ and income changes stemming from distorted factor prices captured by the output elasticity of substitution $\lambda$. Specifically, the impact of tougher credit conditions on welfare depends on $\varepsilon \lambda$. Assuming that the initial capital share $s$ is not high and thus unit labor costs are low and aggregate output is high, then an increase in $\rho$ or $\delta$ decreases aggregate welfare.

Proposition 2. Tighter credit availability captured by higher cost of funds $\rho$ or higher probability of firm default $\delta$ reduces aggregate welfare if the capital share in total costs is not too large.

Another way to see how tighter credit conditions affect the welfare is as follows. Recall from the previous section that the direct utility function can be written as

$$
U=\left((1-\delta) Y y^{-\frac{1}{\varepsilon}}\right)^{\frac{\varepsilon}{\varepsilon-1}}
$$

As discussed earlier, tighter credit conditions decreases both firm output $y$ and aggregate output $Y$; as a result, tighter credit has an ambiguous effect on the aggregate welfare. Where the capital share is not too high, the reduction in the aggregate output $Y$ dominates the increase in $y^{-1 / \varepsilon}$ (caused by a reduction in $y$ ), leading to lower aggregate welfare. Intuitively, firm output affects welfare mainly through labor efficiency by augmenting the effective labor and reducing average production costs. When the share of capital in total costs is not too large (and thus the share of labor is high), output has a more profound affect in firm productivity measured by average production costs. In this case, a reduction in firm output has a higher impact on welfare leading to its decline as firms substitute capital for labor increasing their capital intensity. In contrast, when the share of capital 
in total costs is high, firm productivity is not affected as much by changes in output and welfare increases with lower output (and higher firm capital intensity).

\section{Conclusion}

Some of the greatest challenges facing the US economy are sluggish wage growth and widening income inequality. In this paper, we present a simple model which shows that credit-market frictions can be a catalyst to widening inequality and higher unemployment. In our model, monopolistically competitive firms face credit constraints when financing the cost of production. Credit-market frictions stem from the inability of firms to buy default insurance. In addition, firms use a non-homothetic production technology where labor is more productive at higher scale. This technology translates changes in firm output into changes in factor prices. Finally, labor markets exhibit frictions stemming from job search and matching. Thus, our model presents a unified framework to address (functional) income inequality and unemployment in presence of credit-market imperfections.

Consistent with what we observed during the Great Recession (which was caused by tightening of credit-market conditions associated with the financial crisis), our model predicts that a tighter credit supply widens the gap between wage earners and capital owners; raises the rate of unemployment; and reduces firm-level and aggregate output. When labor is more productive at higher firm output, effective labor costs decline with output expansion. By the same token, during recessionary times as firm output declines, effective cost of hiring labor rises. This leads to substitution towards more capital intensive techniques and a rise in the share of capital in total costs. The increased relative demand for capital raises its reward, and thereby raises the gap between labor and capital earnings. Furthermore, as firms substitute labor with capital, the economy experiences higher unemployment rate. However, as the economy recovers, this process is reversed. As output rises, the gap between the relative earnings of capital and of labor narrow, as seems to be the case in the more recent data. 
The proposed framework can be generalized along several novel dimensions. By adding an explicit distribution of capital among individuals the model can offer insights on how credit availability affects within (as opposed to between) group inequality, especially top incomes. The assumption of symmetric firms can be replaced with heterogeneous firms as in Melitz (2003) where firm profits can constitute another source of income inequality. Finally, recent studies (e.g., Foley and Manova 2015, Dinopoulos et al. 2015) have shown that credit constraints can substantially affect productivity and pattern of trade; consequently, relaxing the closed-economy assumption in the present model will be a fruitful extension.

\section{References}

Acemoglu, Daron, "Credit Market Imperfections and Persistent Unemployment," European Economic Review, 2001, 45, 665-79.

Acemoglu, Daron, "Directed Technical Change," Review of Economic Studies, 2002, 69, 781-809.

Acemoglu, Daron and James A. Robinson, "The Rise and Decline of General Laws of Capitalism," Journal of Economic Perspectives, 2015, 29, 3-28.

Benhabib, Jess, Alberto Bisin, and Shenghao Zhu, "The Distribution of Wealth and Fiscal Policy in Economies with Finitely Lived Agents," Econometrica, 2011, 79, 123-57.

Dinopoulos, Elias, Costas Syropoulos, and Bin Xu, "Intra-Industry Trade and WageIncome Inequality," Journal of International Economics, 2011, 84, 15-25.

Dinopoulos, Elias, Sarantis Kalivitis, and Margarita Katsimi, "Export Pricing and Credit Constraints: Theory and Evidence from Greek Firms," 2015. University of Florida, Mimeo.

Duygan-Bump, Burcu, Alexey Levkov, and Judit Montoriol-Garriga, "Financial Constraints and Unemployment: Evidence from the Great Recession," Journal of Monetary Economics, 2015, 75, 89-105.

Elsby, Michael W. L., Bart Hobijn, and Ayşegül Şahin, "The Decline of the U.S. Labor Share," Brookings Papers on Economic Activity, 2013, Fall, 1-52.

Feenstra, Robert C., Zhiyuan Li, and Miaojie Yu, "Exports and Credit Constraints under Incomplete Information: Theory and Evidence from China," Review of Economics and Statistics, 2011, 96, 729-44. 
Foley, C. Fritz and Kalina Manova, "International Trade, Multinational Activity, and Corporate Finance," Annual Review of Economics, 2015, 7, 119-46.

Hall, Robert E. and Alan B. Krueger, "Evidence on the Incidence of Wage Posting, Wage Bargaining, and on-the-Job Search," American Economic Journal: Macroeconomics, $2012,4,56-67$.

Haskel, Jonathan, Robert Z. Lawrence, Edward E. Leamer, and Mathew J. Slaughter, "Globalization and U.S. Wages: Modifying Classic Theory to Explain Recent Facts," Journal of Economic Perspective, 2012, 26, 119-39.

Jones, Charles I., "Pareto and Piketty: The Macroeconomics of Top Income and Wealth Inequality," Journal of Economic Perspectives, 2015, 29, 29-46.

Jones, Charles I. and Jihee Kim, "A Schumpeterian Model of Top Income and Inequality," 2015. Stanford University, Working Paper.

Karabarbounis, Loukas and Brent Neiman, "The Global Decline of the Labor Share," Quarterly Journal of Economics, 2014, 129, 61-103.

Kopczuk, Wojciech, "What Do We Know About the Evolution of Top Wealth Shares in the United States?," Journal of Economic Perspectives, 2015, 29, 47-66.

Krusell, Per, Lee E. Ohanian, Jose-Victor Rios-Rull, and Giovanni L. Violante, "Capital Skill Complementarity and Inequality: A Macroeconomic Analysis," Econometrica, 2000, 68, 1029-53.

Lawrence, Robert Z., "Recent Declines in Labor's Share in US Income: A Preliminary Neoclassical Account," 2015. Peterson Institute for International Economics, Working Paper.

Melitz, Marc J., "The Impact of Trade on Intra-Industry Reallocations and Aggregate Industry Productivity," Econometrica, 2003, 71, 1695-1725.

Moll, Benjamin, "Inequality and Financial Development: A Power-Law Kuznets Curve," 2012. Princeton University, Working Paper.

Panagariya, Arvind, "Variable returns to scale in production and patterns of specialization," American Economic Review, 1981, 71, 221-30.

Perri, Fabrizio, "Inequality, Recessions and Recoveries," 2013. Federal Reserve Bank of Minneapolis, Annual Report Essay.

Piketty, Thomas and Emmanuel Saez, "Income Inequality in the United States, 19131998," Quarterly Journal of Economics, 2003, 118, 1-39.

Piketty, Thomas, Capital in the Twenty-First Century, Harvard University Press, Cambridge, MA, 2014. 
Piketty, Thomas and Emmanuel Saez, "Inequality in the Long Run," Science, 2014, 344, $838-43$.

Piketty, Thomas and Gabriel Zucman, "Capital Is Back: Wealth-Income Ratios in Rich Countries" Quarterly Journal of Economics, 2014, 129, 1255-1310.

Saez, Emmanuel and Gabriel Zucman, "Wealth Inequality in the United States Since 1913: Evidence from Capitalized Income Tax Data," Quarterly Journal of Economics, 2016, 131, 519-78.

Stiglitz, Joseph E., "Distribution of Income and Wealth Among Individuals," Econometrica, 1969, 3\%, 382-97.

Unel, Bulent, "Analyzing Skilled and Unskilled Labor Efficiencies in the US," Journal of Macroeconomics, 2010, 32, 957-67.

Unel, Bulent, "Offshoring and Unemployment in a Credit-Constrained Economy," 2016. Louisiana State University, Working Paper. 